\title{
Identification of a Novel 14q13.3 Deletion Involving the SLC25A21 Gene Associated with Familial Synpolydactyly
}

\author{
K. Meyertholen ${ }^{\text {a J.B. Ravnan }}{ }^{\text {C }}$ R. Matalon ${ }^{\text {b }}$ \\ ${ }^{a}$ School of Medicine and ${ }^{b}$ Division of Genetics, Department of Pediatrics, University of Texas Medical Branch, \\ Galveston, Tex., and 'Signature Genomics, Spokane, Wash., USA
}

\section{Key Words}

Chromosome $14 \cdot$ Microarray $\cdot$ MIPOL1 $\cdot 2$-Oxoadipate academia • PAX9 • Polydactyly · SLC25A21 - Syndactyly • Synpolydactyly

\begin{abstract}
Synpolydactyly is a relatively rare malformation. Recently, we came across a male infant with a familial synpolydactyly of the hands and feet. As most familial synpolydactyly syndromes have not been linked to any specific mutations, we felt further investigation was warranted. Using microarray and fluorescent in situ hybridization analysis, we identified a novel mutation of the SLC25A21 gene on chromosome 14 .
\end{abstract}

Copyright $\odot 2012$ S. Karger AG, Basel

Synpolydactyly is a rare limb abnormality characterized by a combination of syndactyly, the webbing of adjacent digits with or without bony fusion and polydactyly, the presence of supernumerary digits. The limb abnormalities may occur as an isolated finding or as part of a genetic syndrome and are inherited in autosomal dominant fashion. Several different systems have been created in an attempt to classify syndactyly; the classical nomenclature developed by Temtamy and McKusick [1978] cat- egorizes synpolydactyly as 'syndactyly type II' [Cross et al., 1968]. Many cases of syndactyly have been linked to mutations in the HOX gene clusters; specifically, the HOXD13 gene has been linked to syndactyly type II [Murigaki et al., 1996; Goodman, 2002]. However, the majority of familial syndactyly and synpolydactyly syndromes have yet to be associated with any particular gene mutations. This report describes a male infant with synpolydactyly of the hands and feet. Investigation revealed a family history of synpolydactyly spanning at least 4 generations. Upon further analysis, a deletion within the SLC25A21 gene was identified in the infant and his mother. In addition, no copy number changes were detected at the recognized microdeletion and microduplication syndrome loci or at other clinically significant loci, including the HOXD cluster locus at 2q31.1.

\section{Materials and Methods}

Oligonucleotide- and Microarray-Based Comparative Genomic Hybridization

Microarray-based comparative genomic hybridization was performed using a 135K-feature whole-genome microarray (SignatureChip Oligo Solution ${ }^{\mathrm{TM}}$ version 2.0, custom-designed by Signature Genomics, from Roche NimbleGen, Madison, Wisc., USA), according to previously described methods [Duker et al., 2010].

\section{KARGER}

Fax +4161306 1234

E-Mail karger@karger.ch

www.karger.com
(C) 2012 S. Karger AG, Basel

$1661-8769 / 12 / 0031-0025 \$ 38.00 / 0$

Accessible online at:

www.karger.com/msy
Reuben Matalon

Department of Pediatrics, University of Texas Medical Branch

301 University Boulevard

Galveston, TX 77555 (USA)

Tel. +1 409772 3466, E-Mail rmatalon@utmb.edu 

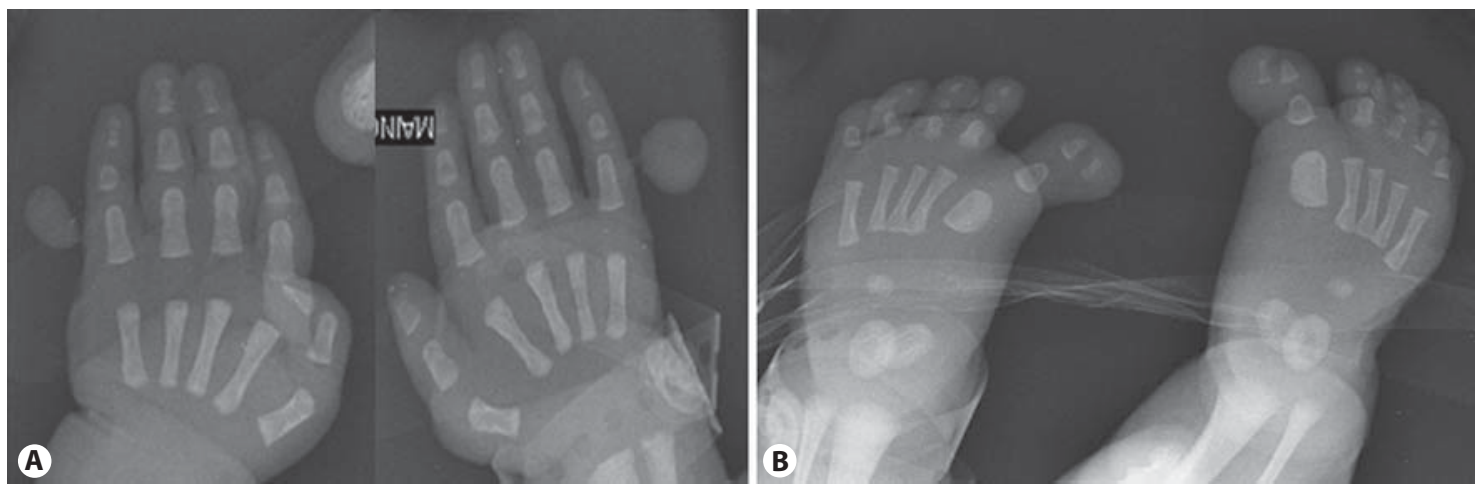

Fig. 1. Radiographs taken on day 1 postpartum. A Polydactyly is noted on the ulnar aspect of both hands with attachment at the proximal 5th phalanges. The extra digit in both hands is composed only of soft tissue with a small punctuate ossification center in its distal aspect. In addition, soft tissue fusion of the proximal third and fourth digits of each hand is seen. B Medial deviation of the great toes with polydactyly noted in the form of an extra distal phalanx on the medial aspect of the great toes.

Fluorescence in situ Hybridization Analysis

Metaphase fluorescence in situ hybridization (FISH) analysis was performed in the proband and his mother using BAC clone CTD-3022B7 from 14q13.3 to visualize the deletion, according to previously described methods [Traylor et al., 2009].

\section{Case Report}

A 2-month-old male was seen in our clinic for evaluation of synpolydactyly of his hands and feet. Radiographs of the hands 1 day postpartum revealed inversion of both thumbs and polydactyly noted on the ulnar aspect of both hands, with extra digits being attached to ulnar margin of the proximal fifth phalanges. The extra digits on both hands were composed of soft tissue with a small punctuate ossification center in the distal aspect. The postaxial polydactyly of the hands was treated with suture ligation 3 days postpartum, prior to our encounter with the patient. Radiographs of the feet revealed a single first metatarsal with evidence of a branched proximal phalanx and duplication of the distal phalanx on the medial aspect of the great toes (fig.1). The proximal phalanx and first metatarsal of both feet were noted to be wider and shorter than normal.

Physical exam of the infant revealed a healthy male with syndactyly of the third and fourth digits of the hands bilaterally, syndactyly of the second and third toes bilaterally, and wide great toes bilaterally. Examination of the ulnar aspects of both of the hands revealed a small nubbin with apical scarring associated with ligation of the supernumerary digits. The remainder of the physical exam revealed no additional abnormalities.

The patient underwent bilateral great toe extra digit excision at 4 months of age. Using an elliptical incision, the primarily cartilaginous extra digit, comprised of a separate distal phalanx and the branched aspect of the proximal phalanx, was dissected and excised on each of the patient's 2 feet. One month after surgery, the patient was reportedly recuperating well.
The patient's mother reported she was born with webbing of the toes and fingers and polydactyly of the hands, which were surgically corrected in childhood. Similar findings have also been found in the maternal grandfather as well several other relatives on the maternal side of the family. Using the family history provided by the patient's mother, we created a pedigree (fig. 2). We were unable to obtain details of the exact nature of each affected family member's presentation, but it is our understanding that synpolydactyly was present in the hands and the feet in most, if not all, of the affected family members.

\section{Results}

Lymphocytes obtained from peripheral blood of the infant were used as a source of DNA, which was then analyzed by microarray and FISH analysis. The microarray analysis identified a copy number change characterized by an $80.6 \mathrm{~kb}$ loss of the long arm of chromosome 14 at $14 \mathrm{q} 13.3$ (fig. 3). FISH analysis confirmed a deletion at 14q13.3 (fig. 4). DNA isolated from the mother's blood also underwent microarray and FISH analysis, and an identical deletion was detected. The deletion is within the SLC25A21 gene and is considered to be the cause of the synpolydactyly.

\section{Discussion}

This patient was found to have a maternally inherited deletion within the SLC25A21 gene. The clinical significance of this deletion is unclear due to a lack of published data implicating copy losses of the SLC25A21 gene in hu- 
Fig. 2. Pedigree of the investigated family. Microarray and FISH analysis demonstrated a deletion of $14 \mathrm{q} 13.3$ in proband (IV:1) and mother (III:2).
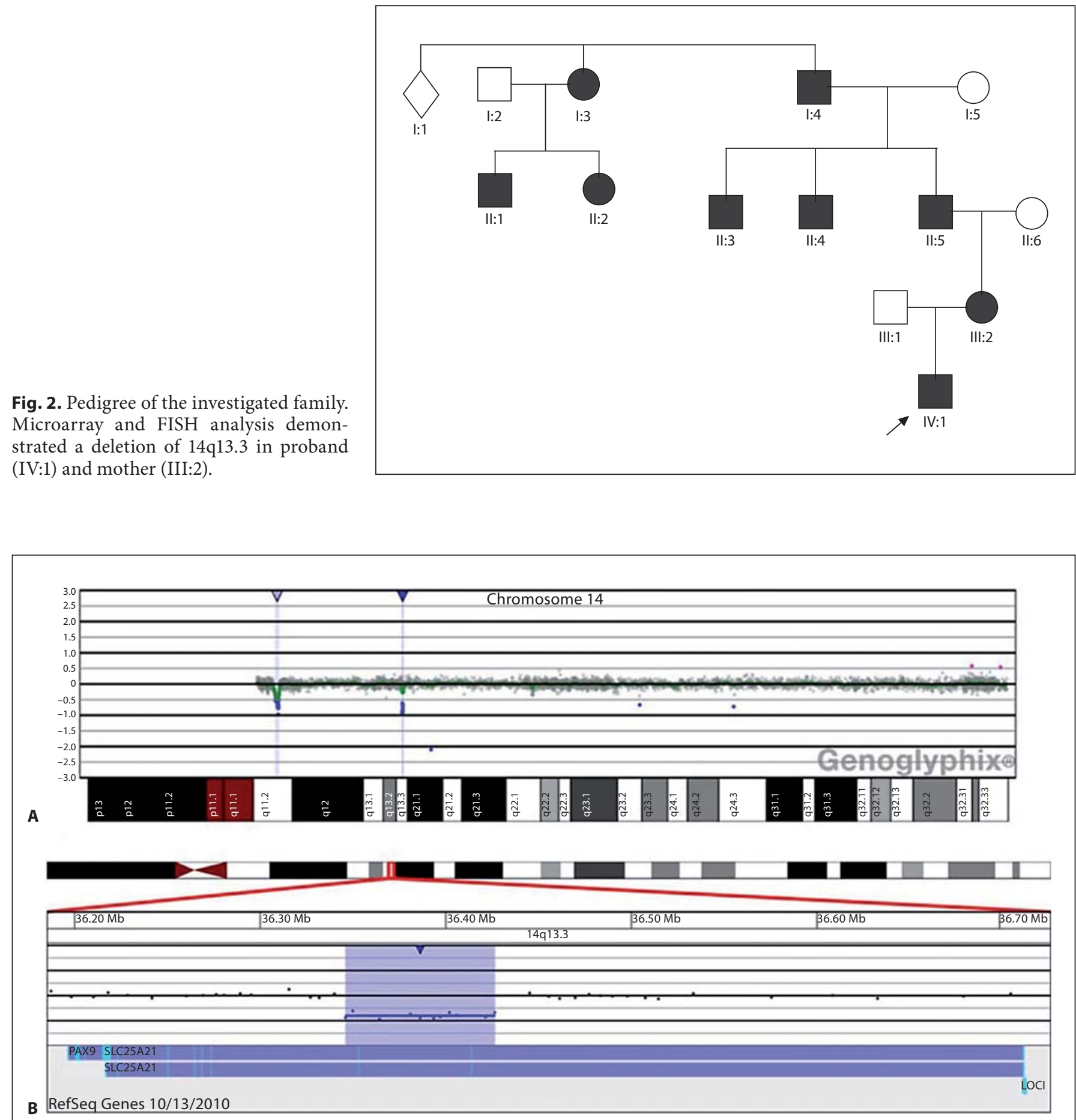

Fig. 3. Microarray characterization of a 14q13.3 deletion. A Microarray plot showing single-copy loss of 11 oligonucleotide probes from the long arm of chromosome 14 at 14q13.3, approximately $81 \mathrm{~kb}$ in size (chromosome 14:36, 346, 051-36, 426, 696, hg18 coordinates). Probes are ordered on the $\mathrm{x}$-axis according the physical mapping positions, with the most proximal q-arm probes to the left and the most distal q-arm probes to the right. Values along the $y$-axis represent $\log 2$ ratios patient:control signal intensifies. B Zoomed-in microarray plot of single-copy loss shown in $\mathbf{A}$. Probes are arranged as in $\mathbf{A}$, with the most proximal $14 \mathrm{q} 13.3$ probes to the right. Genes within the region are displayed as blue boxes, with light blue segments representing exons. Results are visualized using Genoglyphix (Signature Genomics). 
Fig. 4. FISH visualization of a $14 \mathrm{q} 13.3$ deletion in proband and mother. FISH in the proband $(\mathbf{A})$ and mother $(\mathbf{B})$ showing a deletion at 14q13.3. BAC clone CTD-3022B7 from $14 \mathrm{q} 13.3$ is labeled in red, and BAC clone RP11-417P24 from $14 \mathrm{q} 32.33$ is labeled in green as a control. The presence of only one red signal indicated deletion of the $14 \mathrm{q} 13.3$ on one homologue (arrows).
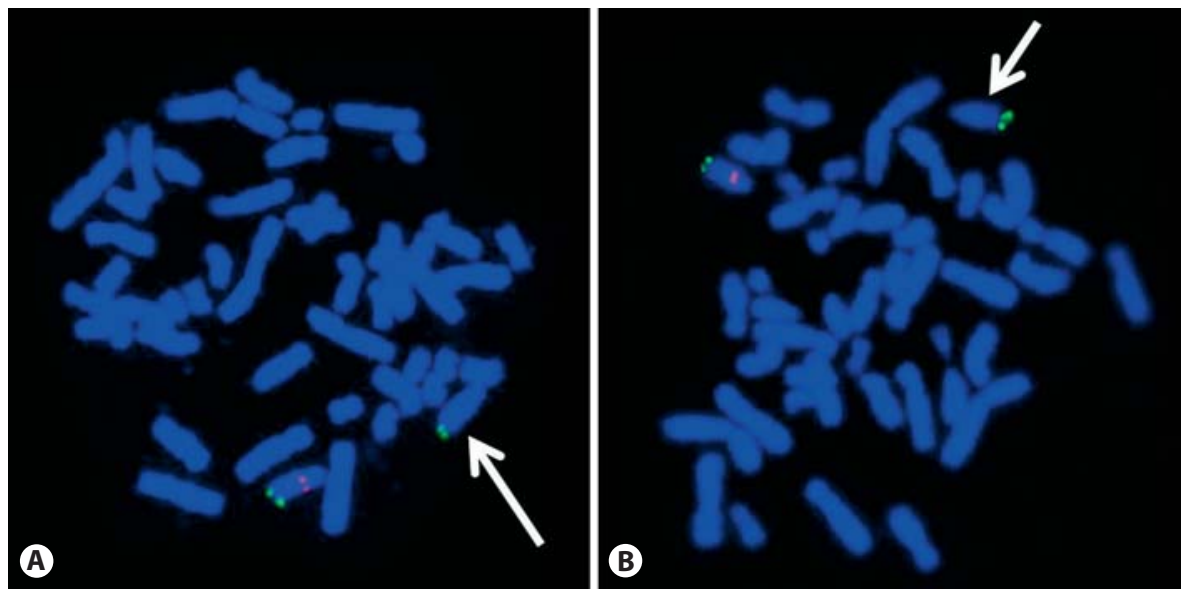

man disease. The gene product, oxodicarboxylate transport is a homolog of the Saccharomyces cerevisiae oxodicarboxylate carrier proteins. These proteins function as mitochondrial carriers that transport C5-C7 oxodicarboxylates across the inner mitochondrial membrane and are present in all tissues. A previous report has identified defects in the SLC25A21 gene product as a possible cause of 2-oxoadipate acidemia, an inborn error of metabolism of lysine, tryptophan, and hydroxylysine characterized by mental retardation, hypotonia and seizures [Fiermonte et al., 2001]. Alternatively, a defective oxoadipate dehydrogenase complex has also been suggested as a cause of 2 -oxoadipate. No studies to date have clearly demonstrated a deficit in either enzyme as causing oxoadipate acidemia. Upon a search of the Database of Chromosomal Imbalance and Phenotype in Humans Using Ensembl Resources (DECIPHER), we found patients with reported deletions encompassing the entirety of the SLC25A21 gene as well as surrounding areas of the genome. The phenotypical manifestations of these patients consist of neurologic abnormalities including ataxia, developmental delay and mental retardation, thyroid abnormalities including hypoplastic or absent thyroid, cleft palate, and oligodontia.

Perhaps of more relevance to this particular case, the SLC25A21 gene is located between the PAX9 and MIPOL1 genes. $P A X 9$ is a member of a transcription factor gene family, whose gene products are known to play essential roles for normal organogenesis and tissue patterning during embryonic development [Dahl et al., 1997]. Appropriate Pax9 expression has been found to be fundamental for the normal development of certain facial structures, of the third and fourth pharyngeal pouch de- rivatives and of the limbs [Peters et al., 1998]. A previously published report described the presence of regulatory elements within the seventh intron of the murine Slc25a21 gene which control Pax9 expression [Santagati et al., 2003]. A separate report described a similar Pax 9 enhancer within the third intron of the Slc25a21 gene in zebrafish [Chatterjee et al., 2011]. In both cases, the regulatory element was detected in a conserved non-coding sequence of the genome.

In a separate report, a patient was described with isolated mirror-image polydactyly and a de novo balanced translocation, $\mathrm{t}(2 ; 14)(\mathrm{p} 23.3 ; \mathrm{q} 13)$ [Kim et al., 1997]. Subsequent investigation found a novel gene that spanned the $14 \mathrm{q} 13$ breakpoint, designated MIPOL1. While the specific function of MIPOL1 is still unknown, it is a strong candidate gene for mirror-image polydactyly [Kondoh et al., 2002]. While it cannot be determined if the deletion described in our patient affects or alters the expression of neighboring genes, the potential interaction between SLC25A21, PAX9 and MIPOL1 is intriguing and further investigation on the relationship between these genes is warranted.

\section{Acknowledgements}

This study employed data generated by the DECIPHER Consortium. A full list of centers who contributed to the generation of the data is available from http://decipher.sanger.ac.uk and via email from decipher@sanger.ac.uk. Funding for the project was provided by the Wellcome Trust. 


\section{References}

Chatterjee S, Bourque G, Lufkin T: Conserved and non-conserved enhancers direct tissue specific transcription in ancient germ layer specific developmental control genes. BMC Dev Biol 11:63 (2011).

Cross HE, Lerberg DB, McKusick VA: Type II syndactyly. Am J Hum Genet 20:368-380 (1968).

Dahl E, Koseki H, Balling R: Pax genes and organogenesis. Bioessays 19:755-765 (1997).

Duker AL, Ballif BC, Bawle EV, Person RE, Mahadevan S, et al: Paternally inherited microdeletion at $15 \mathrm{q} 11.2$ confirms a significant role for the SNORD116 C/D box snoRNA cluster in Prader-Willi syndrome. Eur J Hum Genet 18:1196-1201 (2010).

Fiermonte G, Dolce V, Palmieri L, Ventura M, Runswick MJ, et al: Identification of the human mitochondrial oxodicarboxylate carrier. Bacterial expression, reconstitution, functional characterization, tissue distribution, and chromosomal location. J Biol Chem 276:8225-8230 (2001)
Goodman FR: Limb malformations and the human HOX genes. Am J Med Genet 112:256265 (2002).

Kim KC, Wakui K, Yamagishi A, Ohno T, Sato $M$, et al: Tetramelic mirror-image polydactyly and a de novo balanced translocation be tween 2p23.3 and 14q13. Am J Med Genet 68: 70-73 (1997)

Kondoh S, Sugawara H, Harada N, Matsumoto $\mathrm{N}$, Ohashi $\mathrm{H}$, et al: A novel gene is disrupted at a $14 \mathrm{q} 13$ breakpoint of $\mathrm{t}(2 ; 14)$ in a patient with mirror-image polydactyly of hands and feet. J Hum Genet 47:136-139 (2002).

Muragaki Y, Mundlos S, Upton J, Olsen BR: Altered growth and branching patterns in synpolydactyly caused by mutations in HOXD13. Science 272:548-551 (1996).
Peters H, Neubüser A, Kratochwil K, Balling R: Pax9-deficient mice lack pharyngeal pouch derivatives and teeth and exhibit craniofacial and limb abnormalities. Genes Dev 12: 2735-2747 (1998).

Santagati F, Abe K, Schmidt V, Schmitt-John T, Suzuki M, et al: Identification of cis-regulatory elements in the mouse $\mathrm{Pax} 9 / \mathrm{Nk} \times 2-9$ genomic region: implication for evolutionary conserved synteny. Genetics 165:235-242 (2003).

Temtamy SA, McKusick VA: The genetics of hand malformations. Birth Defects Orig Artic Ser 14:1-619 (1978).

Traylor RN, Fan Z, Hudson B, Rosenfeld JA, Shaffer LG, et al: Microdeletion of 6q16.1 encompassing EPHA7 in a child with mild neurological abnormalities and dysmorphic features: case report. Mol Cytogenet 2:17 (2009). 